\title{
In Situ Analysis Reveals the Role of 2D Perovskite in Preventing Thermal-Induced Degradation in 2D/3D Perovskite Interfaces
}

\author{
Albertus A. Sutanto, Rodrigo Szostak, Nikita Drigo, Valentin I. E. Queloz, P. E. Marchezi, J. C. Germino, \\ Hélio C. N. Tolentino, Mohammad Khaja Nazeeruddin,* Ana Flavia Nogueira,* and Giulia Grancini*
}

Cite This: Nano Lett. 2020, 20, 3992-3998

Read Online

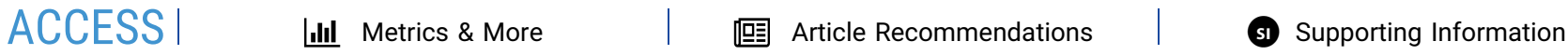

ABSTRACT: Engineering 2D/3D perovskite interfaces is a common route to realizing efficient and stable perovskite solar cells. Whereas $2 \mathrm{D}$ perovskite's main function in trap passivation has been identified and is confirmed here, little is known about its $2 \mathrm{D} / 3 \mathrm{D}$ interface properties under thermal stress, despite being one of the main factors that induces device instability. In this work, we monitor the response of two typical 2D/3D interfaces under a thermal cycle by in situ X-ray scattering. We reveal that upon heating, the $2 \mathrm{D}$ crystalline structure undergoes a dynamical transformation into a mixed 2D/ $3 \mathrm{D}$ phase, keeping the $3 \mathrm{D}$ bulk underneath intact. The observed $3 \mathrm{D}$ bulk degradation into lead iodide is blocked, revealing the paramount role of $2 \mathrm{D}$ perovskite in engineering stable device interfaces.

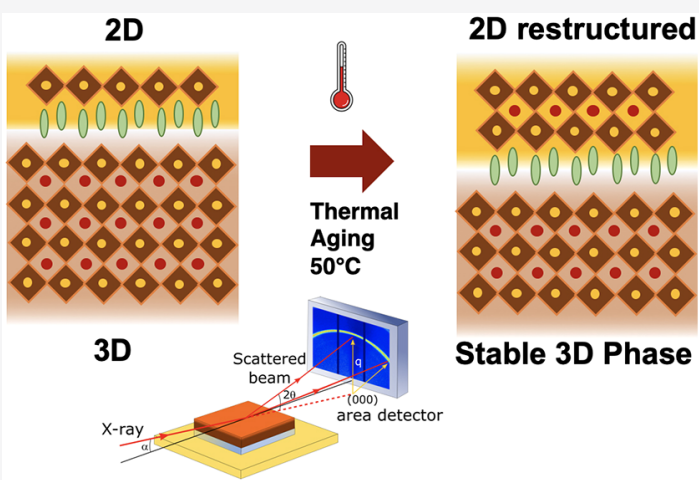

KEYWORDS: perovskite, solar cells, two-dimensional perovskite, three-dimensional perovskite, thermal stress, degradation, stability, GIWAXS, in situ XRD, structure, 2D/3D interface

$\mathrm{W}$ ithin the past decade, hybrid perovskites (HPs) have sat at the forefront of the most recent advances in the area of a new generation semiconductors for cheap optoelectronics, skyrocketing the field of photovoltaics with their power conversion efficiency beyond $25 \% .{ }^{1}$ Critical device stability is currently a well-known issue for market uptake. ${ }^{2-8}$ Behind the most recent advances, engineering multidimensional perovskite interfaces has been revealed as an interesting approach to improving the lifetime of HP devices, mainly due to the improved humidity resistance of the $2 \mathrm{D}$ layer. ${ }^{9-19}$ Examples span from large aminovaleric-acid-based cations, ${ }^{20}$ to widely used phenylethylammonium, ${ }^{21}$ butylammonium iodide, octylammonium iodide, and dodecylammonium iodide (DAI) cations, ${ }^{22}$ to fluorous-based cations ${ }^{23,24}$ synthesized ad hoc to improve robustness against water and, more recently, to thiophene-based cations. ${ }^{25}$ In most cases, 2D perovskites simultaneously act as a surface defect passivant layer and retard charge recombination at the interface with a positive effect on device open-circuit voltage. ${ }^{21-30}$ On top, as previously mentioned, 2D perovskites show high humidity resilience due to their increased chemical stability and hydrophobicity, which slows down device degradation. ${ }^{31-34}$ However, so far, little is known about the role of $2 \mathrm{D}$ perovskite upon thermal stress, which is also a recognized cause of perovskite device degradation. This calls for a deep understanding of the interface behavior upon heating, which is crucial to assess device stability. ${ }^{35}$ Here we address this need by an in-depth investigation of the $2 \mathrm{D} / 3 \mathrm{D}$ film properties during thermal stress, monitoring the structural evolution of the interface and the related optoelectronic and dynamical properties as well as the full device behavior.

We performed combined in situ grazing-incidence wideangle X-ray scattering (GIWAXS) with steady-state and timeresolved photoluminescence (PL) measurements on two study cases of $2 \mathrm{D} / 3 \mathrm{D}$ perovskite systems used in the most common highly efficient device configuration. ${ }^{21,25}$ They consist of a bulky thiophene- or phenyl-terminated cations in the form of 2-thiophenemethylammonium iodide (2-TMAI) or phenylethylammonium (PEAI), forming (2-TMAI) ${ }_{2} \mathrm{PbI}_{4}$ and $\mathrm{PEA}_{2} \mathrm{PbI}_{4} 2 \mathrm{D}$ perovskites, respectively, which overlayer the bulk 3D perovskite. (See Figure 1a.) The structural evolution of the interface is monitored upon exposing the sample to a thermal cycle, simulating the working conditions under real device operation. We reveal that a slow dynamical variation of the $2 \mathrm{D} / 3 \mathrm{D}$ interface manifests, leading to a structural modification of the $2 \mathrm{D}$ perovskite structure. In concomitance, the $3 \mathrm{D}$ perovskite bulk, if protected by the $2 \mathrm{D}$ layer, is unperturbed, whereas in the absence of the $2 \mathrm{D}$ layers, it shows

Received: March 23, 2020

Revised: April 22, 2020

Published: April 30, 2020 
a

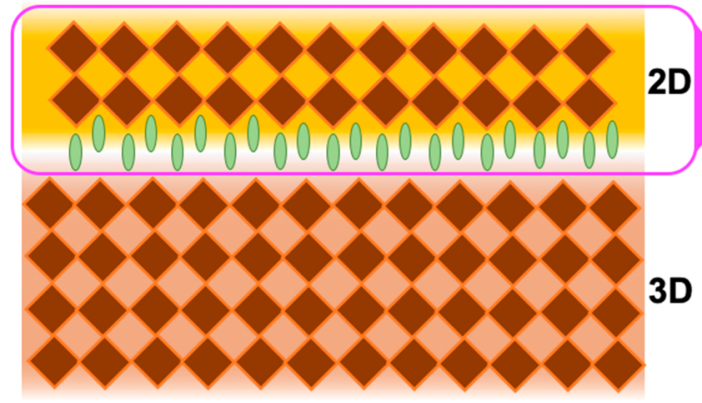

b

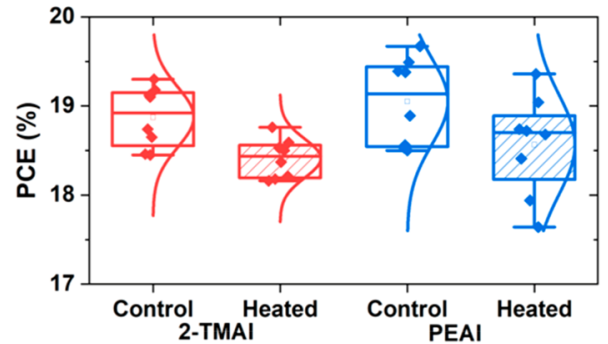

d

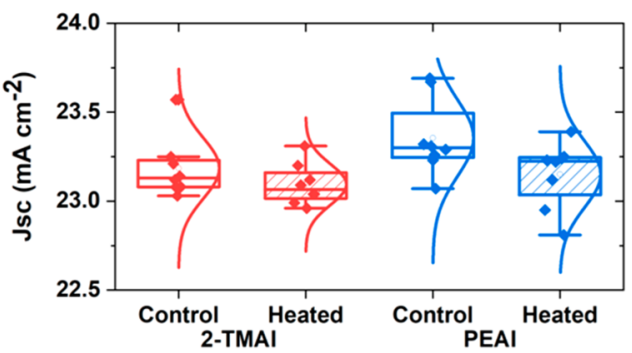

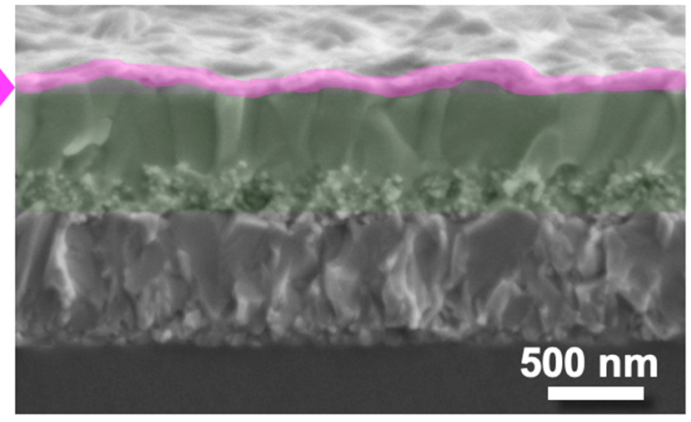

C

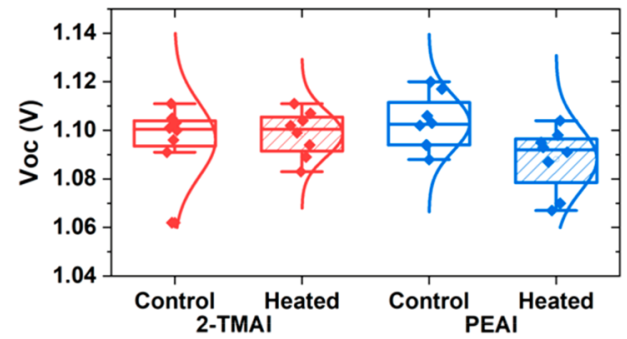

e

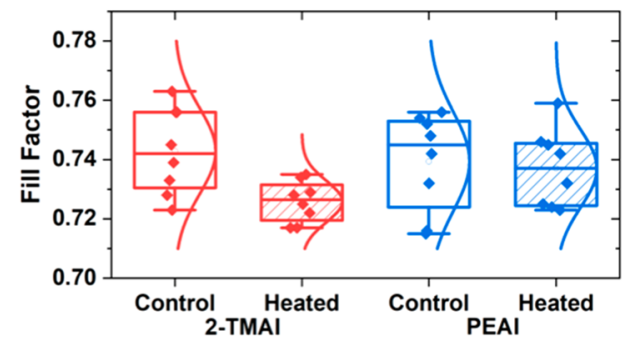

Figure 1. (a) Cartoon of the $3 \mathrm{D} / 2 \mathrm{D}$ interface (left) and the corresponding cross-sectional SEM image of the 3D/2-TMAI 2D interface. (b-e) Statistics of the device photovoltaic properties (PCE, $V_{\mathrm{oc}} J_{\mathrm{sc}} \mathrm{FF}$ ) by comparing the fresh device and the thermally aged devices heated according to the thermal cycle shown in Figure 2.

Table 1. Photovoltaic Parameters of 2D/3D Perovskite Solar Cells Employing PEAI and 2-TMAI as the Bulky Cations (Considering a Statistic of 32 Devices)

\begin{tabular}{lcccc}
\multicolumn{1}{c}{ treatment } & $V_{\mathrm{oc}}(\mathrm{V})$ & $J_{\mathrm{sc}}\left(\mathrm{mA} \mathrm{cm}^{-2}\right)$ & FF & PCE $(\%)$ \\
& & $\mathrm{PEAI} / 3 \mathrm{D}$ & $0.74 \pm 0.02$ & $19.1 \pm 0.5$ \\
control & $1.10 \pm 0.01$ & $23.4 \pm 0.2$ & $0.74 \pm 0.01$ & $18.6 \pm 0.6$ \\
heated $50{ }^{\circ} \mathrm{C}, 100 \mathrm{~min}$ & $1.09 \pm 0.01$ & $23.2 \pm 0.2$ & & \\
& & $2-\mathrm{TMAI} / 3 \mathrm{D}$ & $0.74 \pm 0.02$ & $18.9 \pm 0.3$ \\
control & $1.10 \pm 0.02$ & $23.2 \pm 0.2$ & $0.73 \pm 0.01$ & $18.4 \pm 0.2$ \\
heated $50{ }^{\circ} \mathrm{C}, 100 \mathrm{~min}$. & $1.10 \pm 0.01$ & $23.1 \pm 0.1$ & \\
\hline
\end{tabular}

visible signs of structural degradation. We thus identified a key role of the $2 \mathrm{D}$ capping layer in blocking the thermal degradation of the $3 \mathrm{D}$ perovskite bulk, maintaining its structural integrity and retarding thermally induced degradation in perovskite solar cells.

To create the 2-TMAI- (or PEAI-) 2D/3D thin films and devices, we dissolved the organic salts in isopropanol (IPA) and dynamically spin-coated them on the top of a triple-cation $\left[\left(\mathrm{FAPbI}_{3}\right)_{0.87}\left(\mathrm{MAPbBr}_{3}\right)_{0.13}\right]_{0.92}\left(\mathrm{CsPbI}_{3}\right)_{0.08}$-based 3D perovskite film, where MA stands for methylammonium and FA stands for formamidinium. (See the Supporting Information for details.) As a result, a thin layer of $2 \mathrm{D}$ perovskite $(\sim 60 \mathrm{~nm})$ was formed on top of the $3 \mathrm{D}$ bulk, as shown by the scanning electron microscope (SEM) image in Figure la (right). Whereas the main focus was the study of the interface structural modification, we also fabricated 2-TMAI-2D/3D and PEAI-2D/3D solar cells, and we tested them upon the same thermal cycle as that used for the in situ measurements. Statistics on device current-voltage characteristics and photovoltaic parameters are reported in Figure $1 \mathrm{~b}-\mathrm{e}$ and Table 1, respectively. It is interesting to note that upon thermal stress, the device characteristic is not dramatically affected, showing no massive effect of the thermal stress on the device efficiency. A small decrease is observed only for the device fill factor, which, however, does not dramatically reduce the overall device performance. Table 1 reports the device parameters comparing the fresh and the "heated" device. This contrasts with common knowledge of 3D perovskite solar cells, showing a demonstrated reduction in device performance upon heating. ${ }^{36}$ (See Table S1.)

To get deeper insights into the $2 \mathrm{D} / 3 \mathrm{D}$ interface role under thermal stress and its structural stability, we carried out in situ GIWAXS (measurements performed at the Brazilian Synchrotron National Laboratory (LNLS) in the XRD2 beamline; see 
a
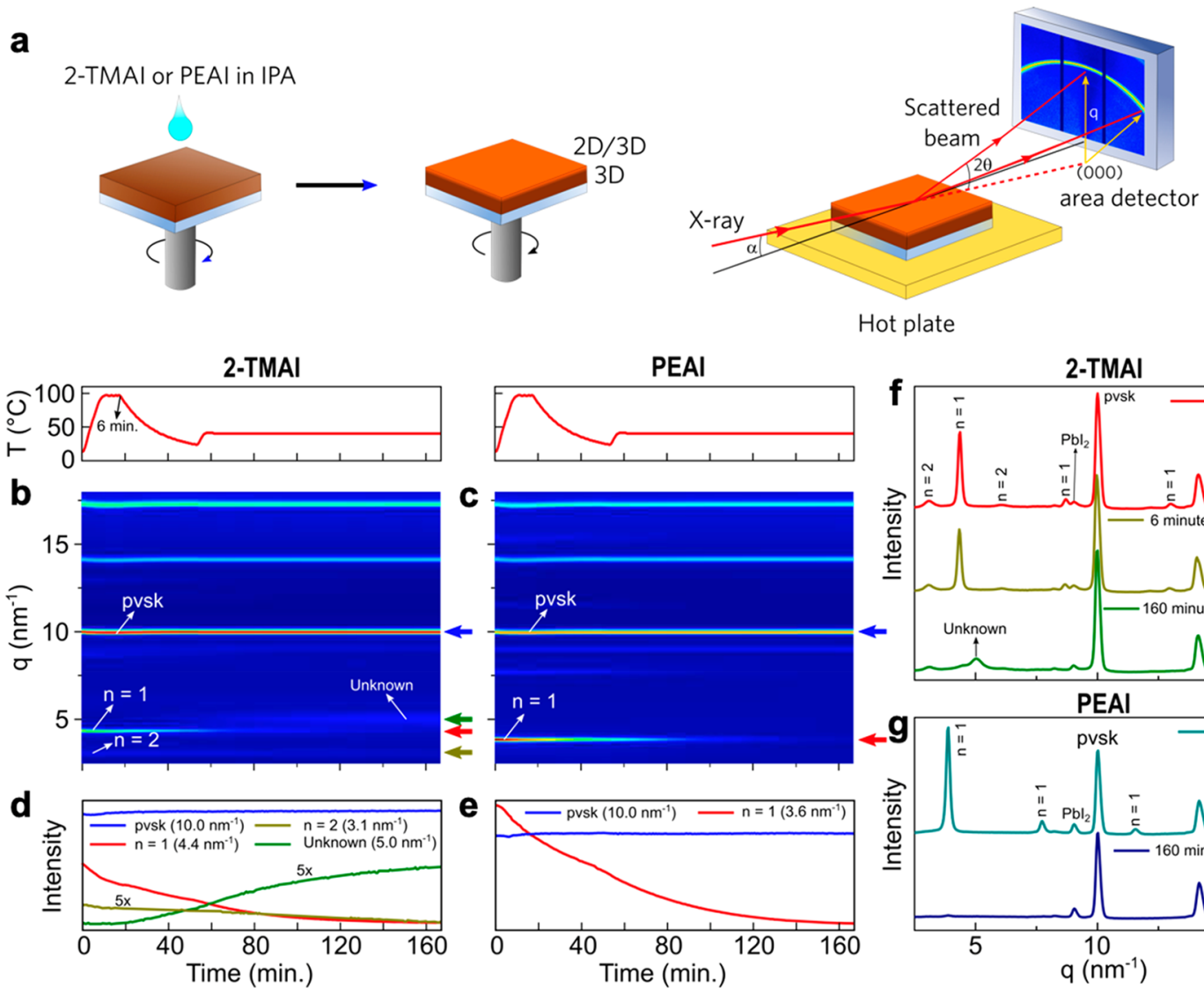

Hot plate

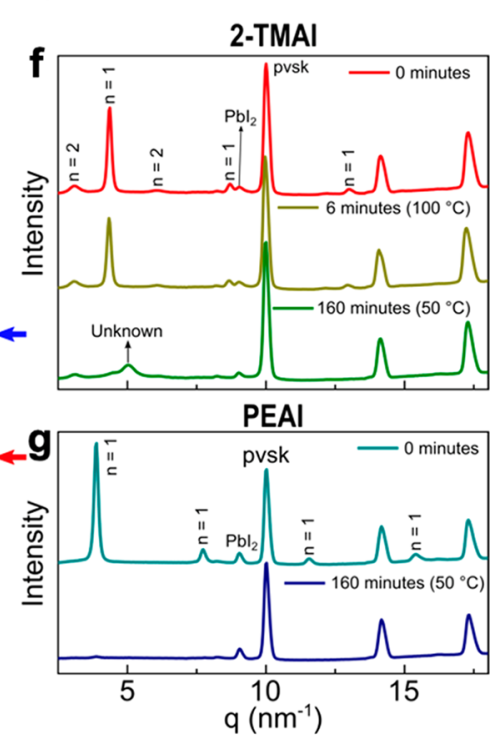

Figure 2. (a) Cartoon drawing illustrating the deposition of $2 \mathrm{D}$ perovskite on top of $3 \mathrm{D}$ perovskite and the schematic drawing of the in situ GIWAXS measurement. (b,c) In situ GIWAXS diffraction maps as a function of time and temperature for 2-TMAI and PEAI modified perovskite (pvsk) films, respectively. (d,e) Respective intensities of the main peaks as a function of time. ( $\mathrm{f}, \mathrm{g})$ Respective X-ray diffraction patterns at different times.

Supporting Information for additional data) during a temperature cycle, as schematically shown in Figure 2a. In particular, the experiment was performed under thermal annealing conditions and an inert atmosphere $\left(\mathrm{N}_{2}\right)$, adopting the following thermal cycle: First, we raised the temperature to $100{ }^{\circ} \mathrm{C}$ after the deposition of the large organic cations and kept it constant for $6 \mathrm{~min}$; then, we decreased it to $50{ }^{\circ} \mathrm{C}$ and kept it constant for $160 \mathrm{~min}$. (See the top chart in Figure 2b,c.)

Upon the spin coating of the $2 \mathrm{D}$ cation on top of the $3 \mathrm{D}$ perovskite, just after dropping the solution and in the beginning of the thermal annealing (Figure $2 \mathrm{f}, 0 \mathrm{~min}$ ), we clearly observed the immediate appearance of new peaks at low $q$ values of 4.4 and $3.1 \mathrm{~nm}^{-1}$ for 2-TMAI. These features correspond to first-order peaks of $2 \mathrm{D}$ perovskite layers. ${ }^{25}$ They refer to a different structure of the $2 \mathrm{D}$ perovskite forming isolated single $(n=1)$ inorganic layers spaced by the large cation, giving the diffraction at $4.4 \mathrm{~nm}^{-1}$, and to a mixed phase (commonly known in literature as quasi-2D or mixed 2D) where more than one inorganic layer (in this case, it is welldefined with $n=2$ ) is held together and intercalated by the large cation, giving the diffraction at $3.1 \mathrm{~nm}^{-1}$, respectively. For the PEAI-2D-based interface, a single $n=12 \mathrm{D}$ phase is formed, leading to the formation of a pure $\mathrm{PEA}_{2} \mathrm{PbI}_{4} 2 \mathrm{D}$ layer, confirmed by the first-order peak at $q=3.6 \mathrm{~nm}^{-1}$.

In both cases, with thermal aging, the intensity of the $n=1$ peak decreases (Figure 2d,e) and vanishes in the time window investigated for $160 \mathrm{~min}$ (Figure 2f,g). This reveals a dynamical change of the $2 \mathrm{D}$ perovskite layer structure under thermal stress, which loses its $n=1$ crystalline phase. In the case of 2-TMAI-2D/3D, the intensity of the $n=2$ peak also decreases (Figure 2d,f); however, in this case, a new peak emerges in concomitance with the reduction of $2 \mathrm{D}$ peaks. This happens after $20 \mathrm{~min}$, manifested as a new broader peak at a $q$ value of $5.0 \mathrm{~nm}^{-1}$ (Figure $2 \mathrm{~b}$, green curve), which keeps increasing during the thermal aging at $50{ }^{\circ} \mathrm{C}$ and reaches a plateau. This peak it is not related to a $2 \mathrm{D}$ phase, as for the comparison of the pure $n=1$ and 2 2-TMAI-based 2D perovskites. (See Figure S1.) Moreover, it is not related to any quasi-2D perovskite with a $n>2$ structure, suggesting that a mixed intermediate structure is formed at the interface. The more detailed procedure for calculating the peaks and their calculated values with $n>2$ can be found in the Supporting Information and in Table S4, respectively.

On the contrary, in the case of PEAI-2D/3D, no further evolution is observed upon thermal aging. Figure 2 also reports the diffraction signal related to the $3 \mathrm{D}$ perovskite structure. It is remarkable to notice that the mutation alters only the $2 \mathrm{D}$ superficial layer, whereas the $3 \mathrm{D}$ perovskite underneath remains unaltered and stable (Figure 2d,e). Repeating the same measurements for the bulk $3 \mathrm{D}$ perovskite, the behavior is strikingly different: In this case (see Figure S2), the 3D peak decreases by $15 \%$ in magnitude, revealing a clear material degradation upon heating, in agreement with common knowledge. On the contrary, when the $2 \mathrm{D}$ overlayer is present (Figure 2d,e), for 2-TMAI and PEAI, no reduction was observed. This provides compelling evidence of the funda- 

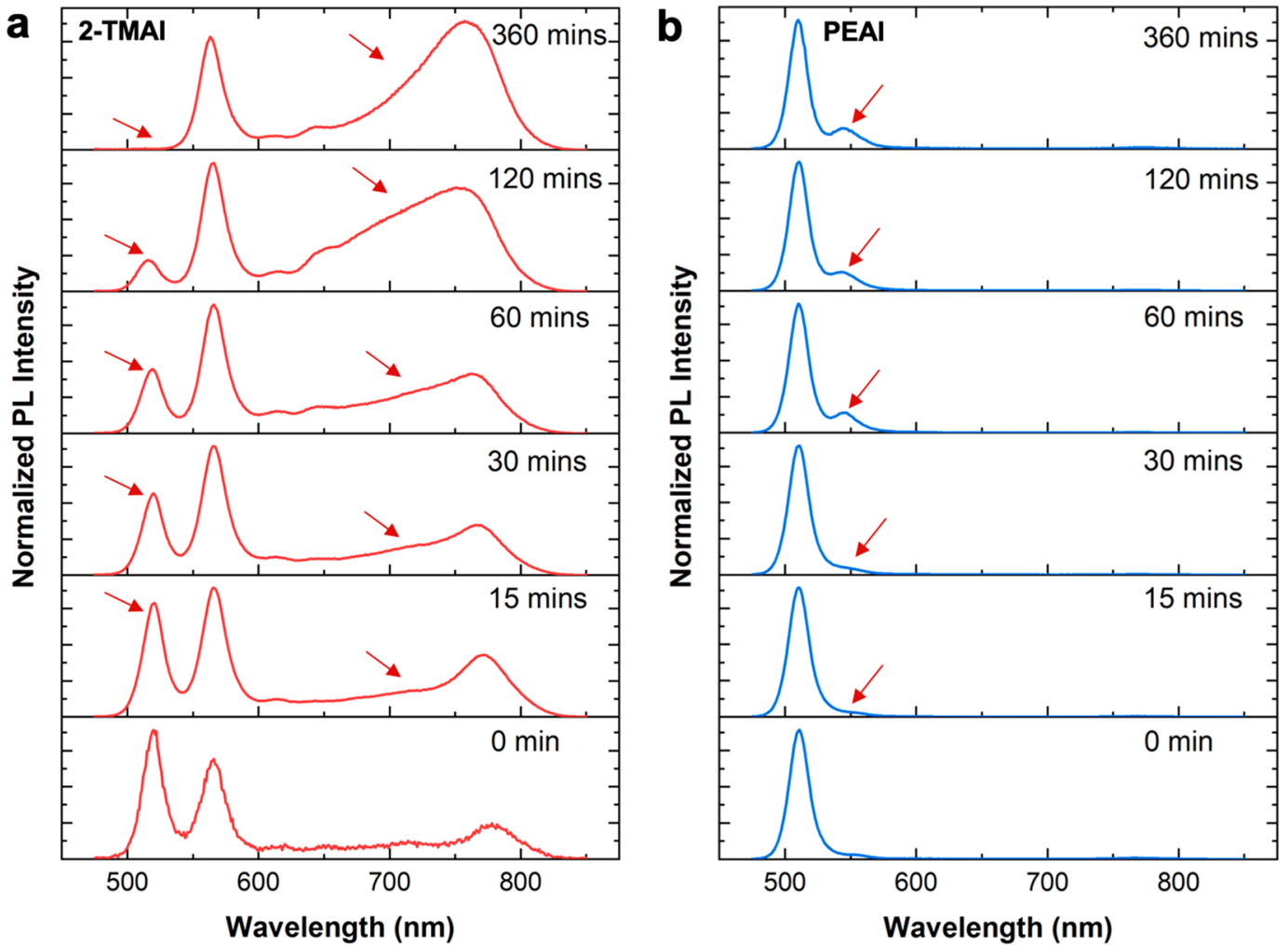

Figure 3. PL spectra of (a) 2-TMAI-2D/3D and (b) PEAI-2D/3D perovskite thin films upon thermal aging at $50{ }^{\circ} \mathrm{C}$ and excitation at $450 \mathrm{~nm}$ from the front (in other words, from the $2 \mathrm{D}$ side).

mental role of the $2 \mathrm{D}$ perovskite in enhancing the robustness of the $2 \mathrm{D} / 3 \mathrm{D}$ system, with a special focus on improving the thermal stability of the 3D perovskite underneath.

To confirm and better elucidate the structural changes in the 2D layer, we monitored the PL spectral evolution as a sensitive probe of the material band gap and the variation thereof, which is indicative of any possible structural change (i.e., $n$ variation), following a similar thermal cycle, as shown in Figure 3.

Because the PL spectra were recorded from the front side (2D perovskite side) of the $2 \mathrm{D} / 3 \mathrm{D}$ film, they mainly show the emission from the $2 \mathrm{D}$ perovskite top layers. The PL measurements were carried out after thermal annealing at $100{ }^{\circ} \mathrm{C}$ and without heating to $50{ }^{\circ} \mathrm{C}$ (time 0 for $\mathrm{PL}$ characterization). At time 0 , the $2-\mathrm{TMAI}-2 \mathrm{D} / 3 \mathrm{D}$ film PL spectrum shows two emission bands centered at 519 and 567 $\mathrm{nm}$, whereas the PEAI-2D/3D film shows only one band at $510 \mathrm{~nm}$ and a small shoulder at $555 \mathrm{~nm}$. According to literature, these bands correspond to the emission from $n=1$ and 2 phases of $2 \mathrm{D}$ perovskites, respectively, ${ }^{25,37}$ in excellent agreement with the GIWAXS results. From the normalized PL spectra reported in Figure 3, it is also evident that for the 2TMAI-2D-based interface a broader emission in the 700-800 $\mathrm{nm}$ spectral range gradually appears during the annealing process. This suggests the formation of a mixed disordered phase, ${ }^{38,39}$ in agreement with the GIWAXS data. On the contrary, for PEAI-2D/3D, the variation of the shape of the PL spectra is less dominant, whereas the absolute intensity (reported in Figure S3a) of the $n=1$ PL peak abruptly diminishes, in agreement with the GIWAXS data. This suggests that PEAI-based 2D perovskite is structurally more robust and less prone to forming a quasi-2D $(n>1)$ phase under this conditions. ${ }^{12,40}$ A similar behavior of the intensity is observed for the 2-TMAI-2D-based interface, showing a decrease in the $n=1 \mathrm{PL}$ peak and a concomitant increase in the broader emission at the longer wavelength side (Figure S3b). These measurements prove the dynamical variation of the $2 \mathrm{D}$ surface perovskite band gap. To gain a deeper understanding of the mechanism behind such dynamical structural/band gap evolution, we also measured the PL spectra of the 2D/3D perovskite films upon aging the film for a long time window of 7 weeks without any heating. The films were stored in a dark and dry environment $(\mathrm{RH}<20 \%)$ at room temperature, and the PL spectra were periodically recorded over time. Interestingly, we observed an analogous modulation of the emission features for both 2-TMAI-2D/3D and PEAI-2D/3D over slow dark aging, as shown in Figure S4. This phenomenon indicates that a similar transformative process happens even at room temperature, over a several weeks time window, while being accelerated under thermal stress. We can rationalize our results considering an intrinsic dynamical evolution of the $2 \mathrm{D} /$ 3D perovskite interface upon aging, which manifest as (i) destructuration of the $2 \mathrm{D}$ perovskite overlayer and (ii) the formation of an additional mixed phase at the interface, both combined with (iii) improved resilience to the degradation of the $3 \mathrm{D}$ perovskite bulk underneath, independent of the $2 \mathrm{D}$ cation used.

Finally, it is worth pointing attention to the fact that device performance with the $2 \mathrm{D}$ overlayer does not dramatically decrease upon heating, despite the interface structural rearrangement. This is due to the role of the $2 \mathrm{D}$ perovskite, which preserves the $3 \mathrm{D}$ bulk nature and function. To better analyze the interfacial processes, we implemented timeresolved PL (TrPL), with the idea of monitoring the chargecarrier dynamics in the 3D bulk upon the thermal cycle. The thermal aging for the TrPL measurement was performed under the same condition as in the steady-state PL measurement. 

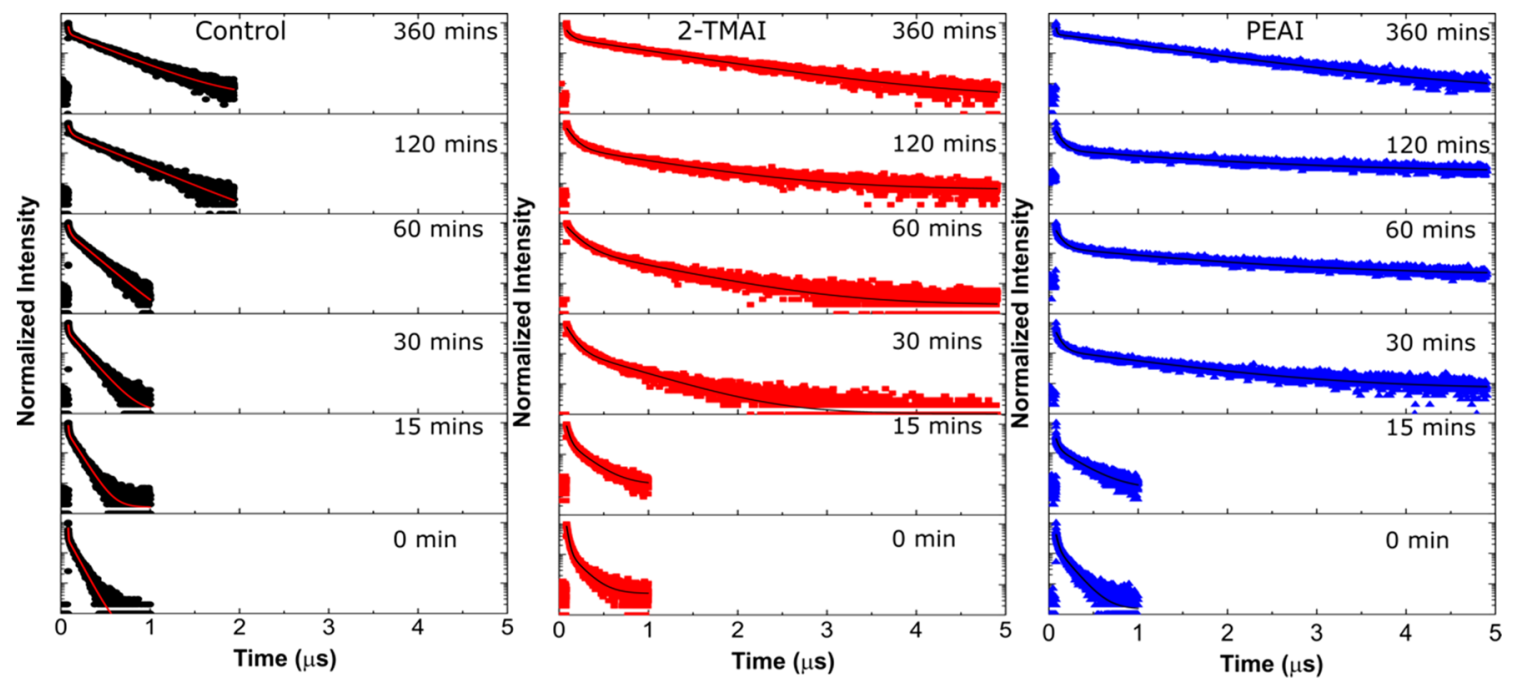

Figure 4. TrPL decays $\left(\lambda_{\text {exc }}=440 \mathrm{~nm} ; F=9.7 \mathrm{~nJ} \mathrm{~cm}^{-2} ; \lambda_{\mathrm{PL}}\right.$ at the maximum of the $3 \mathrm{D}$ at $780 \mathrm{~nm}$ emission at $50{ }^{\circ} \mathrm{C}$ in the samples $)$ of the $2 \mathrm{D} / 3 \mathrm{D}$ modified perovskites: 3D control (black), 2-TMAI (red), and PEAI (blue). The fits of the decays are also shown.

The results are reported in Figure 4 for the 2D/3D interface (blue and red) compared with the controller samples without the $2 \mathrm{D}$ layer. It is worth noting that upon thermal aging, the $\mathrm{PL}$ signal of the bare $3 \mathrm{D}$ film shows an enhancement of the lifetime with a marked long living tail. This happens at time 0 but is even more evident after $15 \mathrm{~min}$ of annealing, and it continues to increase up to $360 \mathrm{~min}$ of thermal aging (Figure $\mathrm{S5}$ ). This is also true for the $2 \mathrm{D} / 3 \mathrm{D}$ interface, where the increase in the lifetime is even more evident. We can attribute the longer living signal to the beneficial effect of the restructuring of the interface, leading to the surface passivation effect and retarded surface charge-carrier recombination. ${ }^{38,41}$

In conclusion, the in situ structural and optical analysis of $2 \mathrm{D} / 3 \mathrm{D}$ perovskite interfaces and devices gives compelling proof of an intrinsic dynamical structural variation of the $2 \mathrm{D}$ perovskite layer after thermal stress, which (i) protects the 3D perovskite from degradation regardless of the $2 \mathrm{D}$ perovskite phase evolution upon heating, (ii) does not perturb the dynamical processes at the interface, and (iii) is beneficial to keeping the device performance unaltered under thermal stress. Our results have highlighted the key role of the $2 \mathrm{D}$ surface functionalization in retarding perovskite degradation upon thermal stress, providing a clear direction on how to gain perovskite device longevity.

\section{ASSOCIATED CONTENT}

\section{SI Supporting Information}

The Supporting Information is available free of charge at https://pubs.acs.org/doi/10.1021/acs.nanolett.0c01271.

Materials and methods, calculation of XRD peak position, Tables S1-S4, and Figures S1-S8 (PDF)

\section{AUTHOR INFORMATION}

\section{Corresponding Authors}

Giulia Grancini - Group for Molecular Engineering of Functional Materials, Institute of Chemical Sciences and Engineering, École Polytechnique Féderale de Lausanne (EPFL), CH-1951 Sion, Switzerland; Department of Chemistry and INSTM, University of Pavia, 27100 Pavia, Italy; 이이.org/ 0000-0001-8704-4222; Email: giulia.grancini@unipv.it
Ana Flavia Nogueira - Laboratório de Nanotecnologia e Energia Solar (LNES), Chemistry Institute, University of Campinas (UNICAMP), Campinas 13083-970, Brazil; Email: anafla@unicamp.br

Mohammad Khaja Nazeeruddin - Group for Molecular Engineering of Functional Materials, Institute of Chemical Sciences and Engineering, Ecole Polytechnique Féderale de Lausanne (EPFL), CH-1951 Sion, Switzerland; 이이.org/ 0000-0001-5955-4786; Email: mdkhaja.nazeeruddin@ epfl.ch

\section{Authors}

Albertus A. Sutanto - Group for Molecular Engineering of Functional Materials, Institute of Chemical Sciences and Engineering, École Polytechnique Féderale de Lausanne (EPFL), CH-1951 Sion, Switzerland; 이이.org/0000-0002-94132789

Rodrigo Szostak - Laboratório de Nanotecnologia e Energia Solar (LNES), Chemistry Institute, University of Campinas (UNICAMP), Campinas 13083-970, Brazil; Brazilian Synchrotron Light Laboratory (LNLS), Brazilian Center for Research in Energy and Materials (CNPEM), Campinas 13083-970, Brazil

Nikita Drigo - Group for Molecular Engineering of Functional Materials, Institute of Chemical Sciences and Engineering, Ecole Polytechnique Féderale de Lausanne (EPFL), CH-1951 Sion, Switzerland

Valentin I. E. Queloz - Group for Molecular Engineering of Functional Materials, Institute of Chemical Sciences and Engineering, Ecole Polytechnique Féderale de Lausanne (EPFL), CH-1951 Sion, Switzerland

P. E. Marchezi - Laboratório de Nanotecnologia e Energia Solar (LNES), Chemistry Institute, University of Campinas (UNICAMP), Campinas 13083-970, Brazil

J. C. Germino - Laboratorio de Nanotecnologia e Energia Solar (LNES), Chemistry Institute, University of Campinas (UNICAMP), Campinas 13083-970, Brazil

Hélio C. N. Tolentino - Brazilian Synchrotron Light Laboratory (LNLS), Brazilian Center for Research in Energy and Materials (CNPEM), Campinas 13083-970, Brazil

Complete contact information is available at: https://pubs.acs.org/10.1021/acs.nanolett.0c01271 


\section{Author Contributions}

A.A.S. fabricated thin films and PSCs and characterized them. N.D. designed and synthesized the organic salts. R.S., P.E.M., J.C.G., and H.C.N.T. performed the in situ GIWAXS analysis. V.I.E.Q. performed PL measurements. J.C.G. performed TrPL measurements. G.G. and A.F.N. conceived the idea. A.A.S., R.S., G.G., and A.F.N. designed the experiments. A.A.S., R.S., G.G., and A.F.N. wrote the manuscript. G.G., A.F.N., and M.K.N. supervised the project. All authors reviewed the paper.

Notes

The authors declare no competing financial interest.

\section{ACKNOWLEDGMENTS}

We thank the LNLS for providing beamtime at the beamline XRD2. R.S. thanks the São Paulo Research Foundation (FAPESP, grant 2017/12582-5). R.S., J.C.G., and A.F.N. gratefully acknowledge support from the FAPESP (grant 2017/11986-5) and Shell and the strategic importance of the support given by the ANP (Brazil's National Oil, Natural Gas and Biofuels Agency) through the R\&D levy regulation. A.F.N. also acknowledges CNPq. We acknowledge the Swiss National Science Foundation (SNSF) funding through the Synergia Grant EPISODE (grant no. CRSII5 171000). G.G. acknowledges the "HY-NANO" project that has received funding from the European Research Council (ERC) Starting Grant 2018 under the European Union's Horizon 2020 research and innovation programme (grant agreement no. 802862).

\section{REFERENCES}

(1) Best Research-Cell Efficiency Chart. https://www.nrel.gov/pv/ cell-efficiency.html (accessed April 30, 2020).

(2) Christians, J. A.; Miranda Herrera, P. A.; Kamat, P. V. Transformation of the Excited State and Photovoltaic Efficiency of $\mathrm{CH} 3 \mathrm{NH} 3 \mathrm{PbI} 3$ Perovskite upon Controlled Exposure to Humidified Air. J. Am. Chem. Soc. 2015, 137 (4), 1530-1538.

(3) Aristidou, N.; Sanchez-Molina, I.; Chotchuangchutchaval, T.; Brown, M.; Martinez, L.; Rath, T.; Haque, S. A. The Role of Oxygen in the Degradation of Methylammonium Lead Trihalide Perovskite Photoactive Layers. Angew. Chem., Int. Ed. 2015, 54 (28), 8208-8212.

(4) Lee, S.-W.; Kim, S.; Bae, S.; Cho, K.; Chung, T.; Mundt, L. E.; Lee, S.; Park, S.; Park, H.; Schubert, M. C.; Glunz, S. W.; Ko, Y.; Jun, Y.; Kang, Y.; Lee, H.-S.; Kim, D. UV Degradation and Recovery of Perovskite Solar Cells. Sci. Rep. 2016, 6 (1), 38150.

(5) Conings, B.; Drijkoningen, J.; Gauquelin, N.; Babayigit, A.; D'Haen, J.; D’Olieslaeger, L.; Ethirajan, A.; Verbeeck, J.; Manca, J.; Mosconi, E.; Angelis, F. D.; Boyen, H.-G. Intrinsic Thermal Instability of Methylammonium Lead Trihalide Perovskite. Adv. Energy Mater. 2015, 5 (15), 1500477.

(6) Yue, Y.; Salim, N.; Wu, Y.; Yang, X.; Islam, A.; Chen, W.; Liu, J.; Bi, E.; Xie, F.; Cai, M.; Han, L. Enhanced Stability of Perovskite Solar Cells through Corrosion-Free Pyridine Derivatives in Hole-Transporting Materials. Adv. Mater. 2016, 28 (48), 10738-10743.

(7) Back, H.; Kim, G.; Kim, J.; Kong, J.; Kim, T. K.; Kang, H.; Kim, H.; Lee, J.; Lee, S.; Lee, K. Achieving long-term stable perovskite solar cells via ion neutralization. Energy Environ. Sci. 2016, 9 (4), 12581263.

(8) Domanski, K.; Correa-Baena, J.-P.; Mine, N.; Nazeeruddin, M. K.; Abate, A.; Saliba, M.; Tress, W.; Hagfeldt, A.; Grätzel, M. Not All That Glitters Is Gold: Metal-Migration-Induced Degradation in Perovskite Solar Cells. ACS Nano 2016, 10 (6), 6306-6314.

(9) Smith, I. C.; Hoke, E. T.; Solis-Ibarra, D.; McGehee, M. D.; Karunadasa, H. I. A Layered Hybrid Perovskite Solar-Cell Absorber with Enhanced Moisture Stability. Angew. Chem. 2014, 126 (42), 11414-11417.

(10) Cao, D. H.; Stoumpos, C. C.; Farha, O. K.; Hupp, J. T.; Kanatzidis, M. G. 2D Homologous Perovskites as Light-Absorbing
Materials for Solar Cell Applications. J. Am. Chem. Soc. 2015, 137 (24), 7843-7850.

(11) Tsai, H.; Nie, W.; Blancon, J.-C.; Stoumpos, C. C.; Asadpour, R.; Harutyunyan, B.; Neukirch, A. J.; Verduzco, R.; Crochet, J. J.; Tretiak, S.; Pedesseau, L.; Even, J.; Alam, M. A.; Gupta, G.; Lou, J.; Ajayan, P. M.; Bedzyk, M. J.; Kanatzidis, M. G.; Mohite, A. D. Highefficiency two-dimensional Ruddlesden-Popper perovskite solar cells. Nature 2016, 536 (7616), 312-316.

(12) Quan, L. N.; Yuan, M.; Comin, R.; Voznyy, O.; Beauregard, E. M.; Hoogland, S.; Buin, A.; Kirmani, A. R.; Zhao, K.; Amassian, A.; Kim, D. H.; Sargent, E. H. Ligand-Stabilized Reduced-Dimensionality Perovskites. J. Am. Chem. Soc. 2016, 138 (8), 2649-2655.

(13) Koh, T. M.; Shanmugam, V.; Schlipf, J.; Oesinghaus, L.; MüllerBuschbaum, P.; Ramakrishnan, N.; Swamy, V.; Mathews, N.; Boix, P. P.; Mhaisalkar, S. G. Nanostructuring Mixed-Dimensional Perovskites: A Route Toward Tunable, Efficient Photovoltaics. Adv. Mater. 2016, 28 (19), 3653-3661.

(14) Hu, Y.; Schlipf, J.; Wussler, M.; Petrus, M. L.; Jaegermann, W.; Bein, T.; Müller-Buschbaum, P.; Docampo, P. Hybrid Perovskite/ Perovskite Heterojunction Solar Cells. ACS Nano 2016, 10 (6), 5999-6007.

(15) Ma, C.; Leng, C.; Ji, Y.; Wei, X.; Sun, K.; Tang, L.; Yang, J.; Luo, W.; Li, C.; Deng, Y.; Feng, S.; Shen, J.; Lu, S.; Du, C.; Shi, H. 2D/3D perovskite hybrids as moisture-tolerant and efficient light absorbers for solar cells. Nanoscale 2016, 8 (43), 18309-18314.

(16) Lai, H.; Kan, B.; Liu, T.; Zheng, N.; Xie, Z.; Zhou, T.; Wan, X.; Zhang, X.; Liu, Y.; Chen, Y. Two-Dimensional Ruddlesden-Popper Perovskite with Nanorod-like Morphology for Solar Cells with Efficiency Exceeding 15\%. J. Am. Chem. Soc. 2018, 140 (37), 11639-11646.

(17) Zhou, T.; Lai, H.; Liu, T.; Lu, D.; Wan, X.; Zhang, X.; Liu, Y.; Chen, Y. Highly Efficient and Stable Solar Cells Based on Crystalline Oriented 2D/3D Hybrid Perovskite. Adv. Mater. 2019, 31 (32), 1901242.

(18) Stoumpos, C. C.; Cao, D. H.; Clark, D. J.; Young, J.; Rondinelli, J. M.; Jang, J. I.; Hupp, J. T.; Kanatzidis, M. G. Ruddlesden-Popper Hybrid Lead Iodide Perovskite 2D Homologous Semiconductors. Chem. Mater. 2016, 28 (8), 2852-2867.

(19) Grancini, G.; Nazeeruddin, M. K. Dimensional Tailoring of Hybrid Perovskites for Photovoltaics. Nat. Rev. Mater. 2019, 4 (1), 422.

(20) Grancini, G.; Roldán-Carmona, C.; Zimmermann, I.; Mosconi, E.; Lee, X.; Martineau, D.; Narbey, S.; Oswald, F.; De Angelis, F.; Graetzel, M.; Nazeeruddin, M. K. One-Year Stable Perovskite Solar Cells by 2D/3D Interface Engineering. Nat. Commun. 2017, 8, 15684.

(21) Cho, K. T.; Grancini, G.; Lee, Y.; Oveisi, E.; Ryu, J.; Almora, O.; Tschumi, M.; Schouwink, P. A.; Seo, G.; Heo, S.; Park, J.; Jang, J.; Paek, S.; Garcia-Belmonte, G.; Nazeeruddin, M. K. Selective Growth of Layered Perovskites for Stable and Efficient Photovoltaics. Energy Environ. Sci. 2018, 11 (4), 952-959.

(22) Kim, H.; Lee, S.-U.; Lee, D. Y.; Paik, M. J.; Na, H.; Lee, J.; Seok, S. I. Optimal Interfacial Engineering with Different Length of Alkylammonium Halide for Efficient and Stable Perovskite Solar Cells. Adv. Energy Mater. 2019, 9 (47), 1902740.

(23) Cho, K. T.; Zhang, Y.; Orlandi, S.; Cavazzini, M.; Zimmermann, I.; Lesch, A.; Tabet, N.; Pozzi, G.; Grancini, G.; Nazeeruddin, M. K. Water-Repellent Low-Dimensional Fluorous Perovskite as Interfacial Coating for $20 \%$ Efficient Solar Cells. Nano Lett. 2018, 18 (9), 5467-5474.

(24) García-Benito, I.; Quarti, C.; Queloz, V. I. E.; Orlandi, S.; Zimmermann, I.; Cavazzini, M.; Lesch, A.; Marras, S.; Beljonne, D.; Pozzi, G.; Nazeeruddin, M. K.; Grancini, G. Fashioning Fluorous Organic Spacers for Tunable and Stable Layered Hybrid Perovskites. Chem. Mater. 2018, 30 (22), 8211-8220.

(25) Sutanto, A. A.; Drigo, N.; Queloz, V. I. E.; Garcia-Benito, I.; Kirmani, A. R.; Richter, L. J.; Schouwink, P. A.; Cho, K. T.; Paek, S.; Nazeeruddin, M. K.; Grancini, G. Dynamical evolution of the 2D/3D interface: a hidden driver behind perovskite solar cell instability. J. Mater. Chem. A 2020, 8 (5), 2343-2348. 
(26) Yoo, J. J.; Wieghold, S.; Sponseller, M. C.; Chua, M. R.; Bertram, S. N.; Hartono, N. T. P.; Tresback, J. S.; Hansen, E. C.; Correa-Baena, J.-P.; Bulović, V.; Buonassisi, T.; Shin, S. S.; Bawendi, M. G. An interface stabilized perovskite solar cell with high stabilized efficiency and low voltage loss. Energy Environ. Sci. 2019, 12 (7), 2192-2199.

(27) Min, H.; Kim, M.; Lee, S.-U.; Kim, H.; Kim, G.; Choi, K.; Lee, J. H.; Seok, S. I. Efficient, stable solar cells by using inherent bandgap of $\alpha$-phase formamidinium lead iodide. Science 2019, 366 (6466), 749-753.

(28) Jung, E. H.; Jeon, N. J.; Park, E. Y.; Moon, C. S.; Shin, T. J.; Yang, T.-Y.; Noh, J. H.; Seo, J. Efficient, Stable and Scalable Perovskite Solar Cells using Poly(3-hexylthiophene). Nature 2019, 567 (7749), 511-515.

(29) Liu, B.; Long, M.; Cai, M.; Ding, L.; Yang, J. Interfacial charge behavior modulation in $2 \mathrm{D} / 3 \mathrm{D}$ perovskite heterostructure for potential high-performance solar cells. Nano Energy 2019, 59, 715720.

(30) Wang, J.; Luo, S.; Lin, Y.; Chen, Y.; Deng, Y.; Li, Z.; Meng, K.; Chen, G.; Huang, T.; Xiao, S.; Huang, H.; Zhou, C.; Ding, L.; He, J.; Huang, J.; Yuan, Y. Templated growth of oriented layered hybrid perovskites on 3D-like perovskites. Nat. Commun. 2020, 11 (1), 582.

(31) Kim, B.; Seok, S. I. Molecular aspects of organic cations affecting the humidity stability of perovskites. Energy Environ. Sci. 2020, 13 (3), 805-820.

(32) Liu, C.; Sun, J.; Tan, W. L.; Lu, J.; Gengenbach, T. R.; McNeill, C. R.; Ge, Z.; Cheng, Y.-B.; Bach, U. Alkali Cation Doping for Improving the Structural Stability of $2 \mathrm{D}$ Perovskite in 3D/2D PSCs. Nano Lett. 2020, 20 (2), 1240-1251.

(33) Wang, K.; Li, Z.; Zhou, F.; Wang, H.; Bian, H.; Zhang, H.; Wang, Q.; Jin, Z.; Ding, L.; Liu, S. Ruddlesden-Popper 2D Component to Stabilize $\gamma$-CsPbI3 Perovskite Phase for Stable and Efficient Photovoltaics. Adv. Energy Mater. 2019, 9 (42), 1902529.

(34) Jia, X.; Zuo, C.; Tao, S.; Sun, K.; Zhao, Y.; Yang, S.; Cheng, M.; Wang, M.; Yuan, Y.; Yang, J.; Gao, F.; Xing, G.; Wei, Z.; Zhang, L.; Yip, H.-L.; Liu, M.; Shen, Q.; Yin, L.; Han, L.; Liu, S.; Wang, L.; Luo, J.; Tan, H.; Jin, Z.; Ding, L. CsPb( $\mathrm{IxBr} 1-\mathrm{x}) 3$ solar cells. Science Bulletin 2019, 64 (20), 1532-1539.

(35) Khenkin, M. V.; Katz, E. A.; Abate, A.; Bardizza, G.; Berry, J. J.; Brabec, C.; Brunetti, F.; Bulović, V.; Burlingame, Q.; Di Carlo, A.; Cheacharoen, R.; Cheng, Y.-B.; Colsmann, A.; Cros, S.; Domanski, K.; Dusza, M.; Fell, C. J.; Forrest, S. R.; Galagan, Y.; Di Girolamo, D.; Grätzel, M.; Hagfeldt, A.; von Hauff, E.; Hoppe, H.; Kettle, J.; Köbler, H.; Leite, M. S.; Liu, S.; Loo, Y.-L.; Luther, J. M.; Ma, C.-Q.; Madsen, M.; Manceau, M.; Matheron, M.; McGehee, M.; Meitzner, R.; Nazeeruddin, M. K.; Nogueira, A. F.; Odabaşı, Ç.; Osherov, A.; Park, N.-G.; Reese, M. O.; De Rossi, F.; Saliba, M.; Schubert, U. S.; Snaith, H. J.; Stranks, S. D.; Tress, W.; Troshin, P. A.; Turkovic, V.; Veenstra, S.; Visoly-Fisher, I.; Walsh, A.; Watson, T.; Xie, H.; Yıldırım, R.; Zakeeruddin, S. M.; Zhu, K.; Lira-Cantu, M. Consensus statement for stability assessment and reporting for perovskite photovoltaics based on ISOS procedures. Nature Energy 2020, 5 (1), 35-49.

(36) Divitini, G.; Cacovich, S.; Matteocci, F.; Cinà, L.; Di Carlo, A.; Ducati, C. In situ observation of heat-induced degradation of perovskite solar cells. Nature Energy 2016, 1 (2), 15012.

(37) Peng, W.; Yin, J.; Ho, K.-T.; Ouellette, O.; De Bastiani, M.; Murali, B.; El Tall, O.; Shen, C.; Miao, X.; Pan, J.; Alarousu, E.; He, J.H.; Ooi, B. S.; Mohammed, O. F.; Sargent, E.; Bakr, O. M. Ultralow Self-Doping in Two-dimensional Hybrid Perovskite Single Crystals. Nano Lett. 2017, 17 (8), 4759-4767.

(38) Motti, S. G.; Crothers, T.; Yang, R.; Cao, Y.; Li, R.; Johnston, M. B.; Wang, J.; Herz, L. M. Heterogeneous Photon Recycling and Charge Diffusion Enhance Charge Transport in Quasi-2D LeadHalide Perovskite Films. Nano Lett. 2019, 19 (6), 3953-3960.

(39) Grancini, G.; Marras, S.; Prato, M.; Giannini, C.; Quarti, C.; De Angelis, F.; De Bastiani, M.; Eperon, G. E.; Snaith, H. J.; Manna, L.; Petrozza, A. The Impact of the Crystallization Processes on the Structural and Optical Properties of Hybrid Perovskite Films for Photovoltaics. J. Phys. Chem. Lett. 2014, 5 (21), 3836-3842.
(40) Moral, R. F.; Bonato, L. G.; Germino, J. C.; Coelho Oliveira, W. X.; Kamat, R.; Xu, J.; Tassone, C. J.; Stranks, S. D.; Toney, M. F.; Nogueira, A. F. Synthesis of Polycrystalline Ruddlesden-Popper Organic Lead Halides and Their Growth Dynamics. Chem. Mater. 2019, 31 (22), 9472-9479.

(41) Bouduban, M. E. F.; Queloz, V. I. E.; Caselli, V. M.; Cho, K. T.; Kirmani, A. R.; Paek, S.; Roldan-Carmona, C.; Richter, L. J.; Moser, J. E.; Savenije, T. J.; Nazeeruddin, M. K.; Grancini, G. Crystal Orientation Drives the Interface Physics at Two/Three-Dimensional Hybrid Perovskites. J. Phys. Chem. Lett. 2019, 10 (19), 5713-5720. 